$\frac{\text { DE }}{\text { DE GRUYTER }}$

\title{
PERFORMANCE THROUGH EFFICIENCY IN THE PUBLIC HEALTHCARE SYSTEM - A DEA APPROACH IN AN EMERGENT COUNTRY
}

\author{
Cristina Silvia NISTOR* \\ Babeș-Bolyai University, Romania \\ Cristina Alexandrina ȘTEFĂNESCU \\ Babeș-Bolyai University, Romania \\ Mara Andreea SîNTEJUDEANU \\ Babeș-Bolyai University, Romania \\ Andrei-Răzvan CRIȘAN \\ Babeș-Bolyai University, Romania
}

\begin{abstract}
Aiming to analyze the efficiency of the public sector, this paper enriches the literature by providing insights of the healthcare system for an emergent country Romania. The empirical findings reached by applying the input orientated-variable return to scale (VRS) model of Data Envelopment Analysis (DEA) and Tobit regression method are determined on two key levels of the study. The Data Envelopment Analysis technique quantifies the efficiency within 20 representative hospitals located in the four administrative macro-regions, highlighting the ways of increasing efficiency, while the Tobit regression identifies the factors that influence the efficiency level. The results of the investigation allow for comparisons with other emerging countries, as efficiency has become an increasingly significant factor for public sector evolution.
\end{abstract}

JEL classification: $\mathrm{H} 41, \mathrm{I18}, \mathrm{M} 40$

Keywords: performance, efficiency, public healthcare system, DEA, emergent country

\footnotetext{
* Corresponding author. Address: Faculty of Economics and Business Administration, BabesBolyai University, Teodor Mihali 58-60, 400591 Cluj-Napoca, Romania, Tel. +40.264 4186 52, Email: cristina.nistor@econ.ubbcluj.ro
} 


\section{Introduction}

Performance management in the public sector is a growing phenomenon worldwide (Goh, 2012) designed to improve public sector accountability (Harrison et al., 2012). It is still facing many problems and challenges in implementing effective measurements, despite multiple frameworks developed over the last decades. Performance measurement is widely seen as the cornerstone of public management reforms (Kong, 2005), being researched in-depth for a long time and comprehensively reviewed (van Helden et al., 2008) for highlighting the relevance of performance measurement and reporting.

Access to performance information enhances users' decision-making and promotes public sector accountability (IPSASB, 2011), which is not simply a one-toone (principal-agent) relationship (Mulgan, 2000). It usually implies different stakeholders whose economic and political interests overlap (Pilcher et al., 2013).

In this context, performance measurement and reporting are a necessary response to public pressure for accountability. Thus, they encourage public entities to disclose publicly and to be responsible for their actions (OECD, 2004), even if there is still no consensus on the real usefulness of performance information (Rossi and Aversano, 2015). Moreover, evidence reveals substantial differences in the adoption of performance measurement and reporting system worldwide, mainly due to the particularities of the institutional, cultural and historical contexts of each country (Benito et al., 2007).

To address this gap, alongside the academic literature, International Public Sector Accounting Standards Board (IPSASB) ensures a strong incentive for promoting the concept of service performance information within public sector entities. Thus, IPSASB published the Recommended Practice Guideline on Reporting Service Performance Information (RPG 4) aiming to develop a framework dedicated to service performance information of public sector entities, meant to enhance accountability for both services provided and resources consumed. Moreover, an essential part of the Conceptual Framework for General Purpose Financial Reporting (GPFR) includes information on performance measurement, thus focusing on service recipients' and the resource providers' needs for high-quality information, for both accountability and decision-making purposes.

Basing on this approach, the primary objective of this study is to provide evidence of the performance assessment in the public sector, by analyzing the efficiency of rendering services, using mathematical techniques and debating potential factors that might affect the outputs, thus leading to inefficiency. Moreover, considering the continuous medical advances, that not only have increased the demand for quality healthcare services but also triggered the challenge of managing rising costs and maintaining efficient operations, the study focuses on the hospital efficiency, one marked in the last decades by serious inefficiencies (Afonso and Aubyn, 2005; Evans et al., 2001; Spinks and Hollingsworth, 2009). Consequently, this study contributes to the prior literature in this field by estimating the technical efficiencies of the hospitals, evaluating the benchmarks and setting the targets for the inefficient hospitals in an emergent country.

For achieving our goal, first of all, we apply a non-parametric technique based on linear programming for assessing the technical efficiency of hospitals, 
namely Data Envelopment Analysis (DEA). Secondly, we resort to the econometric analysis using different statistical tools, like descriptive analysis and regressions to identify those factors with an overwhelming influence on inefficient hospitals.

The sample of our paper consists of 20 public county hospitals in Romania collected from the Centre for Research and Evaluation of Health Services website and the Ministry of Heath's website for the year 2014. Considering the variables used in the previous studies and the availability of data, we have taken the number of beds, the number of doctors and the non-salary operating expenditure as input variables, while the total operating revenues, the number of cases and hospitalization days are considered as output variables.

The results of our DEA model reveal that among all public hospitals in our sample, five are inefficient and for each of these hospitals a benchmark is being provided for improving their operations. The results of a Tobit regression indicate that the number of cases has a positive influence on the efficiency level. Also, variables such as the total operating revenues also present a positive impact on the efficiency score, while non-salary operating expenditures and the number of doctors influence the efficiency level in a negative manner.

The study addresses a broad range of users: theoreticians interested in analyzing emerging countries, as parts of the European Union, and practitioners who manage to find justifications and solutions to similar issues faced in their national systems. Moreover, as the first study that investigates the effectiveness of the health system in this manner, focusing on the main causes of inefficiency in Romania, we appreciate it as a valuable reference base for international literature in the field, too.

The limitations of the study are generated by the sample's dimension and by the period considered for analysis. Thus, the study estimates the efficiencies for half of the county public hospitals in Romania and one calendar year only, which can be extended for time series analysis. Anyway, we appreciate all these as challenges that give us outlooks for future research.

The paper unfolds as follows: at first, the topic of performance and efficiency in the public sector is theoretically approached by analyzing the related literature, from general to specific on public health system (literature review). The next section (methodology framework) develops the concept of efficiency by empirically approaching it from a dual perspective. The efficiency measurement using the multi-criteria nonparametric analysis model known as Data Envelopment Analysis (DEA) is followed by an econometric analysis using various statistical tools to identify those factors with an overwhelming influence on inefficient hospitals. Our analysis ultimately leads to validation or invalidation of research hypotheses (result section), thus reaching conclusions and expressing opinions that respond to papers' primary goal and its objectives (conclusions section).

\section{Literature review and hypothesis development}

According to prior research, there are significant differences in the efficiency of delivering public services across countries, public organizations either being incredibly wasteful and ineffective in performing even core activities or achieving their objectives systematically and comprehensively (Afonso et al., 2005). These differences 
are due to various factors such as fiscal decentralization (Adam et al., 2014), political determinants (Adam et al., 2011), the quality of governance (Hwang and Akdede, 2011), education (Afonso and Fernandes, 2008; Bose et al., 2007), investment and the openness of the economy (Angelopoulos et al., 2008).

Therefore, in the latest decades, the cross-country research studies conducted reveal serious inefficiencies in managing public expenditures (Afonso and Aubyn, 2005; Evans et al., 2001; Spinks and Hollingsworth, 2009), especially in the health sector. In this field, it is expected that public spending on health and social care to increase faster than the economic growth over the next 50 years, in line with recent trends across the OECD (Rumbold et al., 2015). Thus, healthcare systems must find ways of delivering health services at acceptable levels of quality, even with budgets that are growing more slowly than in the past decades. They also have to improve the quality of budgeting and financial management, the key determinants of an effective public spending (Fonchamnyo and Sama, 2015).

Also, the rising healthcare expenditure and large public budgets have recently led decision-makers to search for ways to increase the performance of healthcare organizations. Hospitals, in particular, are increasingly held accountable for their efficiency and financial performance (Tiemann and Schreyögg, 2012), thus supporting the motivation of our study.

This situation manifests itself mainly because healthcare is the part of the public sector where various stakeholders might have different needs and performance embraces a diversity of facets (Harrison et al., 2012). Thus, policy makers have a fiduciary duty to make sure that healthcare expenditure is on a sustainable path. Hospital managers are interested either in improving the quality of the output while using the same amount of resources or in reducing the operation expenses without sacrificing the quality of care provided by the hospital. Instead, doctors and nurses have the responsibility to preserve the safety of their patients and the quality of their work, while patients, as customers of the hospitals, need to be provided with the greatest quality of care (Du et al., 2014).

According to prior research, maximizing efficiency has become an increasingly significant factor for hospital executives, as the possibility for cost savings is better if healthcare institutions are managed appropriately (Harrison et al., 2004; RodriguezAlvarez et al., 2004). Therefore, this study has been taken up to identify the factors that cause inefficiency in the case of the Romanian healthcare sector and to find suitable ways to improve their efficiency.

In this context, the first hypothesis intends to validate the academic literature, which supports the need to maximize the efficiency of using public funds by increasing the quality of services provided (e.g. Harrison et al., 2004; Harrison et al., 2012; Rodriguez-Alvarez et al., 2004):

\section{H1. The Romanian healthcare system is efficient.}

Recently, rising of expenditure on health system reflects only partially the changes in health services demands. These are sometimes represented by new technological innovations in diagnosis and treatment, and therefore in high-quality services, but such progress also comes at a cost. Unfortunately, the evidence reveals that although the technical efficiency has benefited from the embodiment of the new medical technology, the scale efficiency remains unaffected (Tsekourasa et al., 2010). 
Moreover, few innovations in technologies had a substantial impact on reducing costs and improving efficiency (Blank and Van Hulst, 2009).

In this context, there was significant interest in conducting studies in the area of health economics to propose solutions to curb the rapid increase in healthcare spending and to improve the efficiency of the healthcare system. Thus, an insight of the relationship between technology and cost provided relevant results that could influence the long-term cost growth by controlling the availability and diffusion of new technologies (Blank and Van Hulst, 2009). Moreover, most studies analyzing the hospital efficiency focus on technical efficiency (the maximum output given, the input or the minimum input usage given the output), the scale efficiency (the maximum "average product"-i.e., no increasing or decreasing returns), and/or cost efficiency (the minimum cost given, the input prices and the output quantities) and their determinants (Ferrier, et al., 2013).

In this context, our study aims to measure the technical efficiency of public sector hospitals in Romania, to identify the inefficient hospitals and the input reduction required to make them efficient. Consequently, the second hypothesis seeks to validate the positive association between the input and output variables and the efficiency level of the hospitals included in our sample:

H2. There is a positive association between the input and output variables and the efficiency level

In the next sections we develop the hypothesis in order to fulfill the objectives of the study.

\section{Methodology framework}

\subsection{Method}

The performance of the healthcare system is an important issue and has been analyzed in many studies from the efficiency perspective by using a non-parametric analysis model known as Data Envelopment Analysis (DEA). DEA is a non-parametric frontier technique used to search for optimal combinations of outputs and inputs based on the real performance of comparable units (Ozcan, 2008) or decision-making units (DMUs). This approach measures the efficiency by determining the capability of accommodating multiple inputs to produce multiple outputs and also establishes an efficient frontier (a graphics segment generated by the efficient units) as a benchmark for underlying the efficient hospitals and the inefficient ones. Moreover, this method highlights the means of increasing efficiency by indicating what inputs must be reduced or what outputs must be increased so that a hospital reaches the efficiency frontier. In DEA, the maximum output that an enterprise can produce from a set of inputs is estimated from the best performers tracing out the border. This efficiency border can be viewed as a benchmark for assessing the efficiency of an organization (Bryce et al., 2005).

Some studies (Burgess and Wilson, 1996) apply DEA to U.S. hospitals to determine whether the ownership structures - not-for-profit (NFP), for-profit (FP), federal, state, and local government hospitals - influence their technical ability to convert inputs into outputs. Their investigation reveals that FP hospitals are more efficient 
than NFP hospitals and that NFP hospitals are more interested in providing high-quality services rather than obtaining profit. There are authors (Ersoy et al., 1997) who used the constant return to scale model (CRS) to 573 Turkish general hospitals, highlighting that inefficient hospitals use a large number of specialists and primary care physicians, with over two times the number of beds than the efficient ones. However, even with their excess inputs, inefficient hospitals produce fewer outputs than their counterparts. In Germany, public hospitals are more efficient than private ones because they use fewer resources (Helmig and Lapsley, 2001), compared with the significant investments in improving the quality of medical services in private hospitals.

Following prior studies (Bates et al., 2006; Lee et al., 2008; Wang et al., 2010), this research applies the input orientated model to assess the efficiency of using public resources in case of the Romanian county hospitals. Based on available data this study provides evidence on the technical efficiency of 20 public county hospitals in Romania for the year 2014. Given the size, diversity, and complexity of the healthcare services provided by these hospitals, they are among the largest consumers of financial resources in the Romanian Healthcare System.

The last part of our empirical studies uses the Tobit analysis, which is suitable for continuous data that are censored or bounded at a limiting value (Osgood, et al., 2002) and allows for the estimation of the impact of independent variables on the uncensored variables (Wang, et al., 2010).

Tobit regression represents an alternative to the OLS regression and is regularly used in modeling DEA scores (Hoff, 2007). A large number of studies use the Tobit regression procedure in the second stage of the DEA analysis (McDonald, 2009; Simar \& Wilson, 2011). Given that the efficiency scores determined in the first stage of DEA model are between 0 and 1, the use of techniques such as Tobit regression or an exponential function model is preferable, because they are easy to interpret and can accommodate both categorical and continuous variables without changing the number of efficient DMUs (Yang \& Pollitt, 2009).

\subsection{Variables and data}

First of all, aiming to perform a cost-oriented analysis the Romanian public hospitals, we consider the most popular variables for applying DEA in the healthcare system (ÓNeill et al., 2008), thus using similar inputs and outputs for our model (see Table 1).

Table 1. Variables considered for DEA analysis

\begin{tabular}{ll}
\hline Variables & Literature references \\
\hline $\begin{array}{ll}\text { Inputs: } \\
\text { (a) number of beds }\end{array}$ & $\begin{array}{l}\text { Tiemann and Schreyögg (2009); Kirigia, et al. (2008); Staat (2006); } \\
\text { Hu and Huang (2004); Puig-Junoy (2000); Ersoy, et al. (1993); } \\
\text { Valdmanis (1992) }\end{array}$ \\
$\begin{array}{ll}\text { (b) number of doctors } \\
\text { (1993); Valdmanis (1992) }\end{array}$ \\
$\begin{array}{ll}\text { (c) non-salary operating } \\
\text { expenditure }\end{array}$
\end{tabular}




\begin{tabular}{ll}
\hline Variables & Literature references \\
\hline $\begin{array}{l}\text { Outputs: } \\
\text { (d) total operating }\end{array}$ & Lobo, et al. (2014); Du, et al. (2014); Kirigia, et al. (2008) \\
$\begin{array}{ll}\text { revenues } \\
\text { (e) the number of }\end{array}$ & $\begin{array}{l}\text { Du et al. (2014); Staat (2006); Thanassoulis (1993); } \\
\text { cases }\end{array}$ \\
$\begin{array}{ll}\text { (f) hospitalization days (1992) } \\
\text { Lobo et al. (2014) }\end{array}$
\end{tabular}

Source: authors' projection

Following the selection, we provide arguments to support the choice of each variable considered for our model:

(a) Number of beds - is used as a proxy for the hospital size, aiming to determine if managers are using hospital facilities in an efficient and effective way. Prior evidence suggests a positive association between the number of beds and efficiency (Hu and Huang, 2004; Tiemann and Schreyögg, 2009), thus revealing that an increased number of beds improves hospital efficiency.

(b) Number of doctors - is used as a substitute for the labor force. Capital and labor are both imperial in delivering healthcare services in hospitals ( $\mathrm{Ng}, 2011)$. Some studies measured the labor through other related variables, such as the number of physicians, including residents (Puig-Junoy, 2000) or by considering only the inhabitants (Valdmanis, 1992), as well as the number of doctors plus nurses (Kirigia et al., 2008).

(c) Non-Salary operating expenditure (NSOE) - is a new variable introduced in our DEA model as a consequence of prior literature limitations (Kirigia et al., 2008), which did not consider the administrative costs as inputs. We appreciate that physicians are responsible for significant amounts of resource consumption in hospitals and, consequently, they should be accountable for the financial implications of their decisions and actions.

Consequently, regarding the input variable of our study, we use the number of beds and the hospital's expenditure as two separate variables. From the entire hospital's expenditures, we have excluded payroll expenses to avoid the double counting problem (the doctors' incomes), considering that we have already selected the number of doctors as inputs.

(d) Total operating revenues - is used as a financial proxy, measured in other studies by patient admissions (Kirigia et al., 2008) or high complexity procedures (Lobo et al., 2014).

(e) The number of cases. This variable was often used in prior analyses being encountered in various forms, such as the number of patients by age - adult, pediatric, or elderly (Valdmanis (1992), normal/severe patients (Thanassoulis, 1993), including their survival rate (Du, et al., 2014).

(f) Hospitalization days, proven to be positively associated with the number of beds (Lobo et al., 2014).

For the second part of our empirical analysis aimed to identify those factors influencing the efficiency in Romanian public hospitals by using the regression analysis, we consider the efficiency score generated by DEA as the dependent variable and the above-described inputs and outputs as the independent variables. 
Among the results revealed by the prior evidence, we glean that there are significant differences between the efficient and inefficient hospitals regarding the number of beds (Lobo et al., 2014). Moreover, the size of the hospital and the average length of stay have a positive impact, while the ratio of doctors and nurses per patient has an adverse impact (Karagiannis, 2013; Chu and Chiang, 2013).

The sample of our study consists of a reduced sample (20 hospitals) because the minimum number of DMUs that can be used in a DEA model is the number of inputs multiplied by the number of outputs (Boussofiane et al., 1991; Ozcan and McCue, 1996). Also, prior researchers recommend that the number of DMUs should be at least twice (Golany and Roll, 1989) or three times the number of inputs and outputs selected (Bowlin, 1998). In addition to that, Dyson et al. (2001) propose that the total number of units must be two times the product of the number of inputs and outputs.

The selection of hospitals in this study is based on administrative and development considerations. One of the main characteristics of healthcare policy in the public systems is the frequency with which restructurings take place, redefining institutional roles, centralizing or decentralizing, splitting or consolidating different delivery organizations. These reorganizations have a significant impact on the careers of healthcare workers and the quality of the care experienced by the patients (Datta et al., 2013).

The country taken into account for our study is divided into regions, on three levels: NUTS-I, NUTS-II, and NUTS-III. The level NUTS-I consists of four macroregions, the NUTS-II level is composed of eight regions, and the NUTS-III level consists of 41 counties plus the capital of the country (Boldea et al., 2013). The selection of the hospitals is made so that every macro-region is fairly represented in the study. Thus, the sample includes five hospitals from the macro-region 1 , six hospitals from the macro-region 2, four hospitals from macro-region 3 and five hospitals from macro-region 4. It is important to mention that each one of the macroregions consists of a different number of counties.

Following literature recommendation and considering the inputs and outputs variable selected for our study, the minimum number of DMUs should be 9 or 18, so this constraint has been satisfied by our analysis.

The hospitals and variables included in our study are described in Appendix 1.

\subsection{Results and discussions}

In this study, we apply an input-oriented variable returns to scale (VRS) model to measure county hospitals technical efficiency. Our choice of model is based on the assumption that public hospitals have more control over their inputs than over the outputs. According to this model, the inputs are minimalized, and the outputs are kept at their current level (Banker et al., 1984):

$$
\theta^{*}=\min \theta
$$

subject to:

$$
\sum_{j=1}^{n} \lambda_{j} x_{i j} \leq \theta x_{i \mathbf{0}}
$$




$$
\begin{aligned}
& \sum_{j=\mathbf{1}}^{n} \lambda_{j} y_{r j} \geq y_{r_{0}},(r=1,2, \ldots, s) \\
& \sum_{j=\mathbf{1}}^{n} \lambda_{j}=\mathbf{1} \\
& \lambda_{j} \geq \mathbf{0}, j=1,2, \ldots, \mathrm{n}
\end{aligned}
$$

Let $y_{r j}$ be a vector of outputs $(r=1, \ldots, \mathrm{s})$ and $\boldsymbol{x}_{i j}$ a vector of inputs $(i=1, \ldots, m)$ for each hospital $j(j=1, \ldots ., n)$. Since $\theta=1$ is a feasible solution to the optimal value, $\theta^{*} \leq 1$. If $\theta^{*}=1$, then the current input levels cannot be reduced (proportionally), indicating that $D M U_{0}$ is on the frontier. Otherwise, if $\theta^{*}<1$, then $D M U$ o is dominated by the frontier. $\theta^{*}$ represents the (input-oriented) efficiency score of $D M U$.

For a given level of outputs $y_{r}$ and a given level of inputs $x_{i}$ for hospital $\mathrm{O}$, we will determine the input and output slack values by solving the following model (Charnes, at al., 1982):

subject to:

$$
\max \sum_{i=1}^{m} s_{i}^{-}+\sum_{r=1}^{s} s_{r}^{+}
$$

$$
\begin{aligned}
& \sum_{j=\mathbf{1}}^{n} \lambda_{j} x_{i j}+s_{i}^{-}=\theta^{*} x_{i \mathbf{0}},(i=1,2, \ldots, \mathrm{m}) \\
& \sum_{j=\mathbf{1}}^{n} \lambda_{j} y_{r j}-s_{r}^{+}=y_{r 0},{ }_{(r=1,2, \ldots, \mathrm{s})} \\
& \sum_{j=\mathbf{1}}^{n} \lambda_{j}=\mathbf{1}, \\
& \lambda_{j} \geq \mathbf{0},(j=1, \ldots, \mathrm{n})
\end{aligned}
$$

Where $s_{r}^{-}$and $s_{i}^{*}$ represent input and output slacks for $D M U_{0}$ under evaluation and $\lambda_{j}$ is the weight for hospital $j$. This model enables us to analyze inefficiency in each input and each output to have a view on which variable(s) makes a specific DMU be inefficient compared to others. For the current application, we use the VRS (variable returns to scale) DEA model, rather than the CRS (constant returns to scale) one. As a justification for our choice of the model we exemplify the set of slacks we obtained for $D M U_{9}$ by using the CRS version of DEA:

$$
\begin{aligned}
& S_{1 \mathbf{9}=0 ;}^{-} \quad S_{2 \mathbf{g}}^{-}=22.55 ; \quad S_{3 \mathbf{g}=0.45}^{-} \text {; } \\
& S_{19=0}^{+} \quad S_{29=0}^{+} \quad S_{39=9233.84}^{+}
\end{aligned}
$$

These results indicate that for $D M U_{9}$ to reach $100 \%$ efficiency compared with all the other DMUs in the observation set, its hospitalization days should increase with 9233.84 days/ year. In general, a high number of hospitalization days per patient 
is not desirable for a hospital. The purpose of implementing the reimbursement system according to DRGs (diagnosis-related groups) is to reduce the average length of staying, which in the end conducts to an efficient use of a hospital's resources. The DRG scheme classifies patients into a restricted number of medically justified groups, with a statistically stable distribution of resource consumption in each cluster (Thompson et al., 1979).

The descriptive statistics for the study variables is illustrated in Table 2. Note that the variations in most input and output variables are significant. For instance, in the case of bed size, the minimum is 350 beds while the maximum is 1560 beds, with a standard deviation of 360.91 .

Table 2. Descriptive statistics of the inputs and outputs used in the analysis

\begin{tabular}{lcccccccc}
\cline { 2 - 4 } \cline { 7 - 8 } Variables & \multicolumn{3}{c}{ Inputs } & & \multicolumn{3}{c}{ Outputs } \\
\cline { 2 - 4 } \cline { 7 - 8 } & Beds & Doctors & $\begin{array}{c}\text { NSOE } \\
\text { millions) }\end{array}$ & & $\begin{array}{c}\text { TOR } \\
\text { millions) }\end{array}$ & Cases & HD $^{3}$ \\
Mean & 961.45 & 160.52 & 11.57 & & 25.04 & 34603.65 & 226671.50 \\
Maximum & 1560.00 & 345.00 & 29.09 & & 53.33 & 60392.00 & 386226.00 \\
Minimum & 350.00 & 60.00 & 4.00 & & 10.51 & 14644.00 & 81931.00 \\
Std. Dev. & 360.91 & 80.78 & 7.99 & & 14.18 & 13966.77 & 93597.84 \\
\hline
\end{tabular}

$1 \mathrm{EUR}=4.41 \mathrm{RON}$ (Romanian currency)

Where ${ }^{1}$ - Non-salary operating expenditures

2 - Total operating revenues

3 - Hospital days

Regarding the inefficient hospitals, their technical efficiency scores are presented in the second column of Table 3, along with their corresponding slack values.

The non-zero slack values represent resource excesses or wastes regarding inputs and insufficiencies or shortfalls in term outputs. Thus, for increasing the performance, hospitals such as DMU5 and DMU7 should decrease the number of beds, while DMU6, DMU7, and DMU14 should have fewer doctors. few cases.

On the other hand, the results show that all five inefficient hospitals have too

Table 3. Results for DEA model-inefficient DMUs

\begin{tabular}{cccccccc}
\hline Hospital & Technical efficiency & \multicolumn{7}{c}{ Slacks } \\
\hline & & Beds & Doctors & NSOE & TOR & Cases & HD \\
\hline DMU3 & 0.85 & 0.00 & 0.00 & 0.41 & 0.55 & 4625.83 & 0.00 \\
\hline DMU5 & 0.90 & 6.06 & 0.00 & 0.00 & 1.16 & 2326.75 & 0.00 \\
\hline DMU6 & 0.9 & 0.00 & 17.64 & 0.00 & 0.00 & 110.58 & 0.00 \\
\hline DMU7 & 0.97 & 3.85 & 25.32 & 0.00 & 0.00 & 1036.27 & 0.00 \\
\hline DMU14 & 0.84 & 0.00 & 4.33 & 0.00 & 0.00 & 4236.15 & 0.00 \\
\hline
\end{tabular}


The lowest technical efficiency score was registered by DMU14 (0.84). In this context, Table 4 presents a comparative analysis between DMU 14 and DMU 1 , which is considered the benchmark for DMU 14.

Table 4. DMU1 vs. DMU14

\begin{tabular}{ccccccc}
\hline Hospital & \multicolumn{3}{c}{ Inputs } & \multicolumn{3}{c}{ Outputs } \\
\hline & Beds & Doctors & NSOE & TOR & Cases & HD \\
\hline DMU1 & 758 & 116 & 8.58 & 20.76 & 33619 & 205111 \\
\hline DMU14 & 818 & 141 & 8.89 & 18.82 & 23357 & 168845 \\
\hline DMU1-DMU14 & -60 & -25 & -0.31 & 1.94 & 10262 & 36266 \\
\hline
\end{tabular}

Analyzing the table above, we can draw some preliminary conclusions, regarding the discrepancies between DMU1 and DMU14, latter being the most inefficient hospital within our sample.

It can be noticed that, with almost the same budget and less personnel, DMU1 can treat more cases than DMU14 and to support more hospitalization days/year with a lower number of beds. Also, in the case of DMU1, the number of cases/doctor is higher, as average turnover/doctor, the latter being significantly higher. Also, the cost per case and the cost of hospitalization day/case are lower in the case of DMU1, given that the average length of stay is lower for DMU1.

However, taking into consideration that the cases had been validated and the costs for treating these patients had been reimbursed by The National Health Insurance House, as reflected in the total operating revenues (TOR), and also by the average revenue per case, it is plausible to assume that DMU14 is treating more complicated cases than DMU1. Nonetheless, the non-zero slack value for the number of cases provided by the DEA analysis in the case of DMU14 might be explained by the investments performed by this hospital in 2014. Public hospitals receive financial resources that can be used for the specific purpose of purchasing medical equipment, investments, modernization and extension of existing buildings or repairs. These amounts are comprised in the total non-salary operating expenditure, but cannot be used for treating patients. The budget reveals that in 2014, DMU14 invested 8.3 times more in renovations and medical equipment than DMU1. The same link was found in the case of the other three hospitals determined as inefficient by the DEA model (DMU3, DMU5, and DMU6). All these three hospitals invested more in their infrastructure and equipment for improving the quality of medical services.

Prior work also supports these results. In this context, Gok and Sezen (2011) state that one crucial way to increase the efficiency of the Turkish hospitals is by decreasing investments in the health field and/or increasing the production factors, such as the existing beds or physicians (Rezapoor et al., 2011). Moreover, Araújo and his colleagues (2014) argue that high investments in equipment and resources required to treat the patients can generate hospitals' inefficiency. Also, significant investments have the goal to improve the quality and the position of the hospitals against the health insurance companies regarding the budget negotiations (Agai, 2015; 
Helmig and Lapsley, 2001; Hsu, 2010). However, hypothesis H1 can be confirmed, given that $75 \%$ of hospitals included in the sample are efficient, according to the DEA analysis.

The second part of our investigation focuses on determining the factors that might influence the efficiency level. We use the Tobit regression because our dependent variable does not present a continuous structure, mainly taken the values of 0 or 1 . The econometric model must take into consideration the possibility that the dependent variable could be censored/truncated in the extremes of 0 and 1 and the Tobit regression is a classical model that addresses this possibility.

\section{Table 5. The results of Tobit regression}

\begin{tabular}{lrr|lr} 
Variables & Coefficient & \multicolumn{2}{l}{ Std. Error } \\
\hline & & & & \\
LOG (BEGS) & -0.194 & 0.223 & S.D. dependent var & 0.048 \\
LOG (CASES) & $0.618^{\star * *}$ & 0.171 & Akaike info criterion & -0.069 \\
LOG (DOCTORS & $-0.369^{* * *}$ & 0.127 & Schwarz criterion & 0.328 \\
\cline { 4 - 5 } LOG (HOSPDAYS) & -0.369 & 0.263 & Left censored obs & 0 \\
NSOE & $-0.044^{\star * *}$ & 0.014 & Uncensored obs & 5 \\
TOR & $0.037^{\star * *}$ & 0.011 & Right censored obs & 15 \\
& & & Total obs & 20 \\
\hline
\end{tabular}

${ }^{*} \mathrm{p}$-value is $<10 \%$, ${ }^{* *} \mathrm{p}$-value is $<5 \%$, ${ }^{* * *} \mathrm{p}$-value is $<1 \%$

The results provided by the Tobit regression reveal that the number of cases has a positive influence on the efficiency level. In Romania, according to the Health Reform Law no. 95/2006, public hospitals are being funded according to the number of cases validated by the Health Insurance House. In this context, the number of patients positively influences the revenue, while the latter influences the efficiency.

The inadequate infrastructure and outdated medical equipment could raise difficulties in establishing a precise diagnosis, generating waste of resources and leading to inefficiency. This argument is also supported by the results provided by the Tobit regression in the case of NSOE.

As we can notice from the Table 5, the non-salary operating expenditures influence the efficiency level, but the sign reveals a negative correlation, meaning that the lower the level of the expenditures the higher the efficiency score. This result is supported by the insights provided by the DEA model, which highlights that all inefficient hospitals in our sample performed substantial investments in 2014, compared to their benchmarks. Investments in technology, renovations or modernizations are necessary and, even if they could lead to inefficiency, they only have an intermediate effect on the efficiency and do not influence efficiency in the same year (Frohlof, 2007).

Regarding the number of doctors, it appears that this factor influences the efficiency level but in a negative manner. This result is supported by the non-zero slack values provided by DEA for the number of doctors. As we already pointed, a high 
number of doctors within the hospital involves a decrease of the average turnover/doctor and the average number of cases/doctors, and an increase of the salary expenditures, leading to inefficiency. This result is consistent with other prior studies arguing that the ratio of doctors and nurses per patient has an adverse impact (Karagiannis, 2013).

Concerning to the last two factors, prior studies have found a positive association between both the number of beds (Karagiannis, 2013; Lobo et al., 2014) and the hospitalization days (Karagiannis, 2013) and the efficiency score but in our case, no such connection was found. Therefore, hypothesis $\mathrm{H} 2$ can be only partially confirmed.

\section{Conclusions}

The new trends in public sector organizations have recently changed the approach of resources allocation and use, the importance of the public services quality being to the detriment of their quantity. This issue undoubtedly involves assessing the efficiency and performance of the public services. Moreover, public entities gradually became accountable for the services provided and for the resources employed in their activity as a consequence of the worldwide adoption of performance measurement and reporting systems. In this context, a broad range of stakeholders might benefit from this reporting, while allowing all users to assess the entity's service efficiency and effectiveness.

Assessing the performance of the health care system has increasingly become one of the most intensely explored areas of research at international level, due to the severe inefficiencies that marked this sector in the last decades. In this context, our study has an absolute novelty degree for Romania and enriches the literature specific to emergent countries by analyzing the efficiency of public health system, using a sample of 20 selected hospitals from the four Romanian macroregions.

Moreover, we added value to this paper by the methodology employed that successfully combines two research methods. Thus, firstly, we used data envelopment analysis (DEA), by applying the input orientated variable returns to scale (VRS) model, which determines the minimal use of inputs while keeping the outputs constant, based on the assumption that public hospitals have more control over their inputs than over the outputs. Moreover, this model enabled us to analyze inefficiency in each input and each output to have a view on which variable(s) makes a particular decision-making unit (DMU) to be inefficient compared to others. Afterward, a regression analysis was performed, offering a relevant image on how the considered variables influence the efficiency scores within the hospitals included in the sample.

For testing our first hypothesis ( $\mathrm{H} 1)$ we use the number of beds (size), the number of doctors, and non-salary operating expenditure as the input variables and total operating revenues, the number of cases and hospitalization days as output variables. The attained results allow us to conclude that 15 of the considered hospitals are efficient while 5 of them are inefficient. Although the official statistics indicate a lower degree of efficiency in the Romanian health system, our results show that $75 \%$ of the sampled hospitals are efficient. In this case, the first hypothesis $(\mathrm{H} 1)$ is validated by the findings based on DEA. 
Identifying the factors that generate inefficiency demonstrates that efficiency requires not only reducing the allocated resources, but also increasing of the generated results, and consequently it should be a top priority for hospitals operating with limited resources.

Regarding the second hypothesis $(\mathrm{H} 2)$, the results provided by the Tobit regression indicate that the number of hospital cases and the total operating revenues have a positive influence on the efficiency score. On the other hand, the non-salary operating expenditures influence the efficiency level, but the sign reveals a negative correlation. In other words, it means that the lower the level of expenses the higher the efficiency scores. Regarding the number of doctors, this variable influences the efficiency level, but in a negative way. Thus, a large number of doctors in a hospital determine a decrease of the average turnover/doctor and the average number of cases/doctors and, on the other hand, an increase of the salary expenditures leading to inefficiency. Consequently, the second hypothesis $(\mathrm{H} 2)$ is partially confirmed.

In conclusion, the results of the study reveal that the efficiency of the public sector does mean not only the ability to reduce the operating costs but also the capacity to ensure a rational use of resources to obtain the necessary results.

The most significant limitations of the study concern the small size of the sample and the fact that the research regards only one country. Also, the aim of the further research is to investigate the efficiency for a greater number of hospitals from a series of countries, using more input and output variables for the DEA approach.

\section{Acknowledgment}

This work was supported by a grant of the Romanian National Authority for Scientific Research and Innovation, CNCS - UEFISCDI, project number PN-II-RUTE-2014-4-0265.

\section{References}

Adam, A., Delis, M.D. and Kammas, P. (2011) 'Public sector efficiency: leveling the playing field between OECD countries', Public Choice, 146,163-183

Adam, A., Delis, M.D. and Kammas, P. (2014) 'Fiscal decentralization and public sector efficiency: evidence from OECD countries', Economics of Governance, 15(1), 17-49

Afonso A., Schuknecht L. and Tanzi V. (2005) 'Public sector efficiency: an international comparison', Public Choice, 123, 321-347

Afonso, A. and Aubyn, M.S. (2005) 'Non-parametric approaches to education and health efficiency in OECD countries', Journal of Applied Economics, 8(2), 227-246

Afonso, A. and Fernandes, S. (2008) 'Assessing and explaining the relative efficiency of local government', The Journal of Socio-Economics, 37, 1946-1979

Agai, L.A. (2015) The influence of ISO certification on efficiency, customer satisfaction and Service quality in healthcare institutions: The case of the Mater Hospital, A Project Report Submitted To The Chandaria School Of Business In Partial Fulfilment Of The Requirement For The Degree Of Masters In Business Administration (MBA) 
Angelopoulos K., Philippopoulos A. and Tsionas E. (2008) 'Does public sector efficiency matter? Revisiting the relation between fiscal size and economic growth in a world sample', Public Choice, 137(1), 245-278

Araújo, C., Barros, C.P. and Wanke, P. (2014) 'Efficiency determinants and capacity issues in Brazilian for-profit hospitals', Health Care Management Science,17, 126-138

Banker, R.D., Charnes, A. and Cooper, W.W. (1984) 'Some models for the estimation of technical and scale inefficiencies in Data Envelopment Analysis', Management Science, 30, 1078-1092

Bates, L.J., Mukherjee, K. and Santerre, R.E. (2006) 'Market structure and technical efficiency in the hospital services industry: A DEA approach', Medical Care Research and Review, 63(4), 499-524

Benito, B., Brusca I. and Montesinos, V. (2007) 'The harmonization of government financial information systems: the role of IPSASs', International Review of Administrative Sciences, 73(2), 293-317

Blank, J.L. and van Hulst, B.L. (2009) 'Productive innovations in hospitals: an empirical research on the relation between technology and productivity in the Dutch hospital industry', Health Economics, 18(6), 665-679

Boldea, M., Parean, M. and Otil, M. (2012) 'Regional disparity analysis: The case of Romania', Journal of Eastern Europe Research in Business \& Economics, 1, 112

Bose, N., Haque, M.E. and Osborn, D.R. (2007) 'Public expenditure and economic growth: A disaggregated analysis for developing countries', The Manchester School, 75, 533-556

Boussofiane, A., Dyson, R.G., and Thanassoulis, E. (1991) 'Applied Data Envelopment Analysis', European Journal of Operational Research, 52, 1-15

Bowlin, W.F. (1998) 'Measuring performance: An introduction to Data Envelopment Analysis (DEA)', Journal of Cost Analysis, 7, 3-27

Bryce C.L., Engberg J.B. and Wholey D.R. (2005) 'Comparing the agreement among alternative models in evaluating HMO efficiency', Health Services Research, 35(2), 509-528

Burgess J.F. and Wilson P.W. (1996) 'Hospital ownership and technical inefficiency', Management Science, 42(1), 110-123

Charnes, A., Cooper, W.W., Seiford, L. and Stutz, J. (1982) 'A multiplicative model for efficiency analysis', Socio-Economic Planning Sciences, 16(5), 223-224

Chu, H.L. and Chiang, C.Y. (2013) 'The effects of strategic hospital alliances on hospital efficiency', The Service Industries Journal, 33(6), 624-635

Datta, D., Figueira, J.R., Gourtani, A.M. and Morton. A (2013) 'Optimal administrative geographies: an algorithmic approach', Socio-Economic Planning Sciences, 47(3), 247-257

Du, J., Wang, J., Chen, Y. Chou, S. and Zhu, J. (2014) 'Incorporating health outcomes in Pennsylvania hospital efficiency: an additive super-efficiency DEA approach', Annals of Operations Research, 221(1), 161-172

Dyson, R.G., Allen, R., Camanho, A.S., Podinovski, V.V., Sarrico, C.S., and Shale, E.A. (2001) 'Pitfalls and protocols in DEA', European Journal of Operational Research, $132,245-259$

Ersoy, K., Kavuncubasi, S., Ozcan, Y., and Harris, J. (1997) 'Technical efficiencies of Turkish Hospitals: DEA approach', Journal of Medical Systems, 21(2), 67-74 
Eurostat (2007) Regions in the European Union. Nomenclature of territorial units for statistics. NUTS 2006/EU-27, Eurostat Methodologies and working papers.

Evans, D.B., Tandon, A., Muray, C.J.L. and Lauer, J.A. (2001) 'Comparative efficiency of national health systems: Cross national econometric analysis', British Medical Journal, 323, 307-310

Ferrier, G.D., Leleu, H., Moises, J. and Valdmanis, V.G. (2013) 'The focus efficiency of US hospitals', Atlantic Economic Journal, 41(3), 241-263

Fonchamnyo, D.C. and Sama, M.C. (2016) 'Determinants of public spending efficiency in education and health: evidence from selected CEMAC countries', Journal of Economics and Finance, 40(1), 199-210

Frohlof, A. (2007) 'Cost and technical efficiency of German hospitals: A stochastic frontier analysis', iHEA 2007 6th World Congress: Explorations in Health Economics Paper, Ruhr Economic Paper No. 2,

Goh, S. (2012) 'Making performance measurement systems more effective in public sector organizations', Measuring Business Excellence, 16(1), 31-42

Gok, M.S. and Sezen, B (2011) 'Analyzing the efficiencies of hospitals: An application of Data Envelopment Analysis', Journal of Global Strategic Management, 10, 137-146

Golany, B. and Roll, Y. (1989) 'An application procedure for DEA', Omega, 17, 237-250

Harrison, J., Coppola, M.N. and Wakefield, M. (2004) 'Efficiency of federal hospitals in the United States', Journal of Medical Systems, 28, 411-422

Harrison, J., Rouse, P. and de Villiers, C. (2012) 'Accountability and performance measurement: a stakeholder perspective', The Business and Economics Research Journal, 5(2), 243-258.

Parliament of Romania, Law no. 95/2006 on Healthcare Reform https://ec.europa.eu/migrant-integration/librarydoc/romania-law-no-95/2006-onhealthcare-reform (Accessed 1 September 2016)

Helmig B. and Lapsley I. (2001) 'On the efficiency of public, welfare and private hospitals in Germany over time: a sectoral data envelopment analysis study', Health Services Management Research, 14(4), 263-274

Hoff, A. (2007). Second stage DEA: Comparison of approaches for modelling the DEA score. European Journal of Operational Research, 181(1), 425-435.

Hsu, J. (2010) The relative efficiency of public and private service delivery, World Health Report, Background Paper, 39, Health Systems Financing

Hu J.L. and Huang Y.F. (2004) 'Technical efficiencies in large hospitals: a managerial perspective', International Journal of Management, 21(4), 506-513

Hwang, J. and Akdede, S.H. (2011) 'The influence of governance on public sector efficiency: A cross-country analysis', Social Science Journal, 48(4), 735-738

International Public Sector Accounting Standards Board (2011) Consultation paper on 'Reporting service performance information', October 2011

International Public Sector Accounting Standards Board (2013) Exposure Draft 54 'Reporting service performance information', December 2013

Karagiannis, R. (2013) 'A system-of-equations two-stage DEA approach for explaining capacity utilization and technical efficiency', Annals of Operations Research, 227(1), 25-43

Kirigia, J.M., Emrouznejad, A., Cassoma, B., Asbu, E.Z. and Barry, S. (2008) 'A performance assessment method for hospitals: the case of municipal hospitals in Angola', Journal of Medical Systems, 32(6), 509-519 
Kong, D. (2005) 'Performance-based budgeting: the US experience', Public Organizational Review: A Global Journal, 5(2), 91-107

Langabeer, J.R. and Ozcan, Y.A. (2009) 'The economics of cancer care: Longitudinal changes in provider efficiency', Health Care Management Science, 12 (2), 192200

Lee, K.S., Chun, K.H. and Lee, J.S. (2008) 'Reforming the hospital service structure to improve efficiency: Urban hospital specialization', Health Policy, 87(1), 41-49

Lobo, M.S., Ozcan, Y.A., Lins, M.P.E., Silva, A.C.M and Fiszman, R. (2014) 'Teaching hospitals in Brazil: Findings on determinants for efficiency', International Journal of Healthcare Management, 7(1), 60-68

McDonald, J. (2009). Using least squares and tobit in second stage DEA efficiency analyses. European Journal of Operational Research, 197(2), 792-798.

Mulgan, R. (2000) 'Accountability: An ever-expanding concept?', Public Administration, 78(3), 555-573

Ng, Y.C. (2011) 'The productive efficiency of Chinese hospitals', China Economic Review, 22, 428-439

Organisation for Economic Cooperation and Development (2004), Public sector modernisation: governing for performance.

http://www.oecd.org/site/govgfg/39044817.pdf (Accessed 1 September 2016)

ÓNeill L, Rauner M, Heidenberger K. and Kraus M. (2008) 'A cross-national comparison and taxonomy of DEA based hospital efficiency studies', Socio-Economic Planning Sciences, 42(3), 158-189

Osgood, D.W., Finken, L.L. and McMorris, B.J. (2002) 'Analyzing multiple-item measures of crime and deviance II: Tobit regression analysis of transformed scores', Journal of Quantitative Criminology, 18(4), 319-347

Ozcan Y.A. (2008) Health care benchmarking and performance evaluation: an assessment using data envelopment analysis (DEA), International Series in Operations Research and Management Science. Springer Science and Business Media, LLC New York, NY

Ozcan, Y.A. and McCue, M. J. (1996) 'Development of a financial performance index for hospitals: DEA approach', Journal of the Operational Research Society, 47(1), 18-26

Pilcher, R., Gilchrist, D., Singh, I. and Singh, H. (2013) 'The interface between internal and external audit in the Australian public sector', Australian Accounting Review, 23(4), 330-340

Puig-Junoy, J. (2000) 'Partitioning input cost efficiency into its allocative and technical components: an empirical DEA application to hospitals', Socio-Economic Planning Sciences, 34(3), 199-218

Rezapoor, A., Shokuh, M. H., \& Faradonbeh, S. B. (2014). Studying effects of production factors in hospitals affiliated with Tehran University of Medical Sciences (2008-2011). Journal of Health Policy and Sustainable Health, 1(2).

Rodriguez-Alvarez, A., Fernandez-Blanco, V. and Knox Lovell, C.A. (2004) 'Allocative inefficiency and its cost: the case of Spanish public hospitals', International Journal of Production Economics, 92, 99-111

Rossi, F.M. and Aversano, N. (2015) 'Advancing performance measurement Italian local government vis-à-vis the IPSASB project', International Journal of Productivity and Performance Management, 64(1), 76-93 
Rumbold, B.E., Smith, J.A, Hurst, J., Charlesworth, A. and Clarke, A. (2015) 'Improving productive efficiency in hospitals: findings from a review of the international evidence', Health Economics, Policy and Law, 10, 21-43

Simar, L., \& Wilson, P. W. (2011). Two-stage DEA: caveat emptor. Journal of Productivity Analysis, 36(2), 205.

Spinks, J. and Hollingsworth, B. (2009) 'Cross-country comparisons of technical efficiency of health production: A demonstration of pitfalls', Applied Economics, 41, 417427

Staat, M. (2006) 'Efficiency of hospitals in Germany: a DEA-bootstrap approach', Applied Economics, 38(19), 2255-2263

Thanassoulis, E. (1993) 'A comparison of regression analysis and data envelopment analysis as alternative methods for performance assessments', Journal of the Operational Research Society, 44(11), 1129-1144

Thompson, J.D., Averill, R.F. and Fetter, R.B (1979) 'Planning, budgeting, and controllingOne look at the future: case-mix cost accounting', Health Care Services Research, 14, $111-125$

Tiemann O. and Schreyögg, J. (2012) 'Changes in hospital efficiency after privatization', Health Care Management Science, 15(4), 310-326

Tiemann O. and Schreyögg J (2009) 'Effects of ownership on hospital efficiency in Germany', Business Research, 2(2), 115-145

Tsekourasa, K., Papathanassopoulosb, F., Kounetasa, K. and Pappousc, G. (2010) 'Does the adoption of new technology boost productive efficiency in the public sector? The case of ICUs system', International Journal of Production Economics, 128(1), 427-433

Valdmanis, V. (1992) 'Sensitivity analysis for DEA models: An empirical example using public vs. NFP hospitals', Journal of Public Economics, 48(2), 185-205

van Helden, J., Johnsen, Å. and Vakkuri, J. (2008) 'Distinctive research patterns on public sector performance measurement of public administration and accounting disciplines', Public Management Review, 10(5), 641-651

Wang, M.T., Selman, R.L., Dishion, T. J. and Stormshak, E.A. (2010) 'A tobit regression analysis of the covariation between middle school students' perceived school climate and behavioral problems', Journal of Research on Adolescence, 20 (2), 274-286

Yang, H., \& Pollitt, M. (2009). Incorporating both undesirable outputs and uncontrollable variables into DEA: The performance of Chinese coal-fired power plants. European Journal of Operational Research, 197(3), 1095-1105. 


\section{Appendix 1. Database used in methodological framework}

Efficient Input Target

\begin{tabular}{|c|c|c|c|c|c|c|}
\hline $\begin{array}{c}\text { DMU } \\
\text { No. }\end{array}$ & $\begin{array}{l}\text { Macro- } \\
\text { region }\end{array}$ & $\begin{array}{l}\text { DMU } \\
\text { Name }\end{array}$ & BEDS & DOCTORS & NSOE & CASES \\
\hline 1 & 2 & Vrancea & 758,00000 & 116,00000 & 8,58495 & $20,7558233619,00000205111,00000$ \\
\hline 2 & 4 & Valcea & 1353,00000 & 0188,00000 & 9,50317 & $24,1546550336,00000348936,00000$ \\
\hline 3 & 4 & Caras Severin & 716,31682 & 103,80160 & 7,60433 & $18,5212530929,83489188047,00000$ \\
\hline 4 & 4 & Gorj & 1009,00000 & 0164,50000 & 4,79383 & $16,3668234996,00000216608,00000$ \\
\hline 5 & 1 & Bistrita & 884,46650 & 114,04461 & 7,70951 & $18,7403133234,75458222298,00000$ \\
\hline 6 & 1 & Satu Mare & 1041,08228 & 8146,73290 & 9,47163 & $24,1376437612,58666262496,00000$ \\
\hline 7 & 1 & Sf. Gheorghe & 577,39858 & 61,61965 & 4,10940 & $10,7909321649,27969128554,00000$ \\
\hline 8 & 2 & Constanta & 1560,00000 & 0261,50000 & 25,96371 & $47,9444255704,00000345380,00000$ \\
\hline 9 & 3 & Ilfov & 350,00000 & 85,00000 & 5,37311 & $10,5178314644,0000081931,00000$ \\
\hline 10 & 3 & Slobozia & 510,00000 & 69,00000 & 4,00944 & $11,3453818848,00000101119,00000$ \\
\hline 11 & 3 & Giurgiu & 514,00000 & 71,00000 & 4,67945 & $10,9613516714,00000121708,00000$ \\
\hline 12 & 3 & Calarasi & 571,00000 & 60,00000 & 4,09705 & $10,5723421611,00000127762,00000$ \\
\hline 13 & 3 & Alexandria & 725,00000 & 99,00000 & 4,39478 & $15,8600922501,00000146723,00000$ \\
\hline 14 & 4 & Hunedoara & 693,53751 & 115,21423 & 7,53949 & $18,8197427593,15740168845,00000$ \\
\hline 15 & 1 & Baia Mare & 920,00000 & 205,00000 & 14,96380 & $32,3648037305,00000220297,00000$ \\
\hline 16 & 4 & Timisoara & 1174,00000 & 0318,00000 & 29,09891 & $53,3350644759,00000304770,00000$ \\
\hline 17 & 2 & Braila & 1215,00000 & 0172,00000 & 17,55910 & $38,0777543539,00000311973,00000$ \\
\hline 18 & 1 & Cluj & 1542,00000 & 0345,00000 & 26,18240 & $53,0284860392,00000386226,00000$ \\
\hline 19 & 2 & Bacau & 1444,00000 & 0235,00000 & 18,63741 & $36,6387853414,00000321631,00000$ \\
\hline 20 & 3 & Prahova & 1199,00000 & 0171,00000 & 12,77506 & $29,6509045007,00000323015,00000$ \\
\hline
\end{tabular}

